\title{
Global connections and the structure of skills in local co-worker networks
}

\author{
László Lőrincz ${ }^{1,2^{*}} \mathbb{0}$, Guilherme Kenji Chihaya ${ }^{3,4} \mathbb{0}$, Anikó Hannák ${ }^{5}$, Dávid Takács ${ }^{3}$, Balázs Lengyel ${ }^{1,2,6}$ \\ and Rikard Eriksson ${ }^{3,7}$
}

*Correspondence:
lorincz.laszlo@krtk.mta.hu
${ }^{1}$ Centre for Economic
and Regional Studies,
Institute of Economics,
Budapest, Hungary
Full list of author information
is available at the end of the
article

*Correspondence: lorinczlaszlo@krtk.mta.hu and Regional Studies, Institute of Economics, Budapest, Hungary article

\begin{abstract}
Social connections that reach distant places are advantageous for individuals, firms and cities, providing access to new skills and knowledge. However, systematic evidence on how firms build global knowledge access is still lacking. In this paper, we analyse how global work connections relate to differences in the skill composition of employees within companies and local industry clusters. We gather survey data from 10\% of workers in a local industry in Sweden, and complement this with digital trace data to map co-worker networks and skill composition. This unique combination of data and features allows us to quantify global connections of employees and measure the degree of skill similarity and skill relatedness to co-workers. We find that workers with extensive local networks typically have skills related to those of others in the region and to those of their co-workers. Workers with more global ties typically bring in less related skills to the region. These results provide new insights into the composition of skills within knowledge-intensive firms by connecting the geography of network contacts to the diversity of skills accessible through them.
\end{abstract}

Keywords: Co-worker networks, Skills, Relatedness, Global connections, Survey, Online social network

\section{Introduction}

Understanding the role of networks in the various domains of social and economic life is one of the central challenges for science today (e.g., Borgatti et al. 2009; Lazer et al. 2009). Social networks are proven to inform us about how information spreads (Bakshy et al. 2012; Helbing et al. 2015), about the role of social influence on individual behaviour (Aral and Nicolaides 2017; Ugander et al. 2012), and the impact of social network structure on the performance of teams (Guimera et al. 2005; Vedres 2017), among other things.

Despite recent years' advancements in Big Data, most of our knowledge about social networks is still based on either small samples and case studies, or large-scale analyses, thus neglecting the very geography inscribed in all socio-economic relations (Fernandez and $\mathrm{Su}$ 2004). Nevertheless, the spatial structure of networks is decisive for understanding the role of networks in society. For example, social connections that reach distant places, compared to more local connections, are commonly perceived to be crucial in

c) The Author(s) 2020. Open Access This article is licensed under a Creative Commons Attribution 4.0 International License, which permits use, sharing, adaptation, distribution and reproduction in any medium or format, as long as you give appropriate credit to the original author(s) and the source, provide a link to the Creative Commons licence, and indicate if changes were made. The images or other third party material in this article are included in the article's Creative Commons licence, unless indicated otherwise in a credit line to the material. If material is not included in the article's Creative Commons licence and your intended use is not permitted by statutory regulation or exceeds the permitted use, you will need to obtain permission directly from the copyright holder. To view a copy of this licence, visit http:// creativecommons.org/licenses/by/4.0/. 
the generation of wealth for individuals, firms, and communities by providing access to opportunities and diverse knowledge (Bailey et al. 2019; Eagle et al. 2012; Eriksson and Lengyel 2019; Fitjar and Rodriguez-Pose 2011). However beneficial so-called "long ties" might be, these distant-and presumably weak-ties are highly dependent on the local capacity to absorb and internalize external information. Research on information flows and innovation, for example, shows that distant ties tend to be most beneficial when combined with cohesive local networks that can efficiently process complex information (Aral 2016; Bathelt et al. 2004; Granovetter 1973; Ter Wal et al. 2016; Tóth and Lengyel 2019).

The skills and knowledge of the workforce are defining assets of the firm, and are directly related to internal and external collaboration. We have ample evidence that firm performance depends extensively on how employees' skills are combined (Abdulkareem et al. 2018; Boschma et al. 2009; Dibiaggio et al. 2014). The efficiency gains generated by the division of labour in the firm and the consequent skill specialization naturally depend on the extent of the knowledge residing in the firm that fosters employees' specialization (Neffke 2019) but are counterbalanced by coordination costs that also increase with the extent of the knowledge (Becker and Murphy 1992). Firm specialization itself is also seen as a net outcome of the advantages of focusing on special tasks in the firm and the costs of transferring this special knowledge to the outside world (Kogut and Zander 1993). Although transferring knowledge across firm boundaries usually comes with extra costs, inter-firm collaborations enable specialized firms to access complementary resources (Madhok 2002) or external sources of information (e.g., Tortoriello and Krackhardt 2010). However, previous research on advice networks in local industries has found that firms tend to collect knowledge from co-located firms that are similar to them in terms of knowledge or applied technologies (Balland et al. 2016; Juhász and Lengyel 2018). In economic geography, it is widely accepted that network formation driven by technological similarity threatens local economies with a scenario of lock-in that harms productivity and resilience (Boschma and Frenken 2010; Grabher 1993; Hassink 2010). In this understanding, global links can feed local dynamics by adding new varieties of skills (Bathelt and Turi 2011; Glückler 2007).

Previous research has explored the combination of firms' existing skills with new skills by investigating flows of skilled labour (Breschi and Lissoni 2009; Eriksson and Lindgren 2009). The conclusive claim is that a complementarity of incoming workers' skills and the skills already present in the firm boosts performance (Boschma et al. 2009; Csáfordi et al. 2020; Ter Wal et al. 2016). At the individual level, complementary skills within the firm have been found to increase wages (Neffke 2019). In this body of literature, geography plays an important role because distant knowledge flows via labour mobility bring in additional novelty, arising from the differences in geographical locations (Boschma et al. 2009).

Of course, labour mobility is not independent from collaboration networks (Tzabbar et al. 2018). As employees maintain social relations with former co-workers, labour mobility creates social networks between firms. Recent contributions have quantified the probability of co-worker relationships within regions (Lengyel and Eriksson 2017) and shown that the internal networks in industry regions largely determine whether more diverse or specialized linkages to other sectors and regions are promoting growth 
(Eriksson and Lengyel 2019). Hence, social relations-that is, the main mechanism enhancing interactive learning (Arrow 1962) which also tends to be the most localized type of interaction (Singh 2005) - are likely to be highly influential in structuring firms' skill combination. However, so far, data limitations have prevented us from understanding how global knowledge access matches the skill composition of co-worker networks within firms. The literature on knowledge flows has neither assessed the origin of skills nor gone beyond the formal knowledge captured in educational degrees or industry experience.

The aim of this paper is therefore to conduct a systematic analysis of how the structure and skill content of social networks within firms match with local and global networks, respectively. To address this problem, we first investigate how employees' skills are related by being linked in the advice network within firms and in an online social network across firms. Subsequently, we turn to the relationship between the geography of social networks and skills. The aim of the paper is summarized in two research questions:

Research Question 1: How are co-workers' skills and advise-seeking relations within firms related?

Research Question 2: Do workers who have extensive global connections offer new skills to the firm compared to workers who are embedded in local networks?

Extensive previous research has assessed the evolution of organizational advice networks, arguing that tie formation in these networks is driven by status and individual characteristics (e.g. Lazega and Van Duijn 1997; Agneessens and Wittek 2012), value similarity (Lazega et al. 2012), or team membership (Brennecke and Rank 2016). However, extensive research on the skill structure within firms and advice networks is still lacking. An exception is Brennecke and Rank (2017), who investigate how the knowledge of inventors-measured using the technological profile of their patent portfolio-at a large firm influences their connections in their advice network. They find that knowledge similarity facilitates the formation of advice relations, while diverse individual knowledge increases the probability of being asked for advice by, and decreases the probability of asking for advice from, a colleague.

Our contribution to this literature is twofold. First, we assess how co-workers' skills in general-without focusing on inventors-are related to being connected in advice networks within and across firms in the region. Second, we explore the interplay of the distant social connections and the skill structure in local co-worker networks.

This analysis is enabled by collecting survey data at the firm level and combine it with online data. We asked all employees of 16 ICT (information, communication and technology) firms in Umeå, Sweden (representing $10 \%$ of the local industry), to name the co-workers with whom they collaborate and socialize, and from whom they ask professional advice. Additionally, we asked for the respondents' permission to collect public information from their LinkedIn profiles. These data collection techniques allow us to quantify the geographical reach of the connections (Park et al. 2019) and to measure the skill complementarity of co-workers based on how similar and related their skills are (Neffke and Henning 2013). 
We find that co-workers are more likely to ask advice from colleagues if their skills are similar or related. A further result suggests that workers with extensive local networks typically have skills that are related to those of peers in the region and to those of coworkers within the firm. On the contrary, workers with a high proportion of distant ties have skills that are only loosely, or not at all, related to those of connections in the region and in the firm. Finally, we find that shared education abroad is a more important factor for creating global ties than foreign work experience. These results provide new insights into the composition of skills within knowledge-intensive firms by connecting the geography of networks and the similarity or diversity of skills.

\section{Data and methods}

We collected network data on 214 IT workers at 16 ICT firms using a workplace survey in Umeå, Sweden. Besides being part of a knowledge-intensive industry, the ICT cluster in Umeå is located in a relatively peripheral position (ca. $1000 \mathrm{~km}$ north of the capital of Stockholm) and yet is unusually connected to the rest of the world due to the existence of a fast-growing university there. This makes it a good case for studying the importance of distant ties in providing skill diversity to local industries.

Our firm sample population consisted of all ICT firms with main offices in the Umeå region and which had more than ten IT workers. A list of ICT companies with offices in the Umeå region was obtained from a local business incubator (Uminova). Of the 77 companies on the list, 17 were excluded because they had fewer than ten IT workers on their payroll and 24 were excluded because their main office was not in the Umeå region. Of the remaining 36 companies, 14 declined to collaborate, and six wanted to collaborate but were unable to do so during our fieldwork period. This resulted in 16 out of 36 companies matching the sample requirements being surveyed, yielding a $44.4 \%$ response rate on the firm level. Within the firms, the response rate of employees exceeded $80 \%$ at every firm. The resulting sample consisted $21 \%$ women and $79 \%$ men, and $93 \%$ having college degree. Comparing these to administrative data of the ICT firms in Umea, women are underrepresented in the sample (35\% women in the register data), and college educated are overrepresented (60\% in the register). This difference may be due to that we distributed the questionnaire to the professional staff, excluding auxiliary service workers like cleaners, secretaries, and accountants.

The survey included questions on demography (gender, country of birth), the job (current position at the firm, department, promotion), satisfaction with different aspects of the work, and co-worker networks. In respect to network questions, De Lange et al (2004) analysed 17 questions used in organizational network studies and revealed three main dimensions using factor analysis: advice, social support-companionship, and friendship. Considering time constraints and sensitivity, we chose three questions with similar logic but tapping into different dimensions-information, socialization, and cooperation-and asked these using the full roster method. ${ }^{1}$ In this study the focus is on asking for professional advice, as advice is related to direct information channels.

\footnotetext{
${ }^{1}$ The questions were worded as follows in our study: (1) Who are the people you need to collaborate with in your current projects in order to get your work done? Pick as many of your co-workers as you like. (Click on a name to select and click again to de-select.) (2) Who are the people who give you important information to get your current projects done? Pick as many of your co-workers as you like. (3) Who are the people you socialize with outside work-related situations? Pick as many of your co-workers as you like.
} 

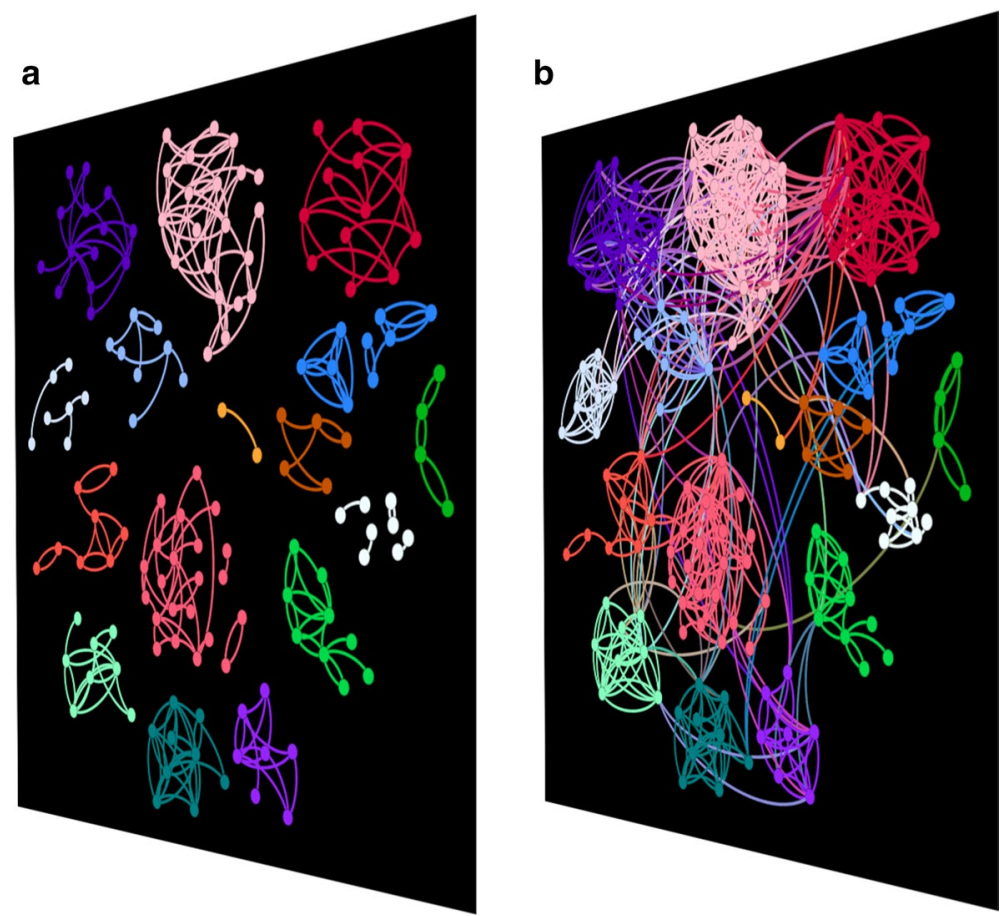

Fig. 1 Connections of respondents. a Connections in the information networks within firms. Colours represent firms. $\mathbf{b}$ Linkedln connections added to advice network. The colour of inter-firm edges is set on a dyadic level as the interpolation of the nodes' colours. Linkedln connections cluster within firms, but a significant number of bridges connect the firms of the cluster

With the respondents' consent to access their LinkedIn profiles, we collected detailed information about their skills, employment, and education histories. Our LinkedIn subscription allowed us to collect similar data from the respondents' network connections, including location. Due to a number of incomplete surveys and missing variables, we collected complete skills data on 150 respondents, as well as the connections, education, and work histories of 125 respondents.

Advice networks within firms and additional LinkedIn connections across respondents are displayed in Fig. 1. Ties in the advice networks are directed. This implies that there might be two edges between two nodes when both respondents have indicated the other as a source of information (Fig. 1a). Although the number of respondents varies considerably between three and 25 , these networks are relatively similar in terms of edge density (mean equals 0.21 with $95 \%$ confidence interval $[0.14 ; 0.28]$ ) and average path length (mean equals 1.61 with 95\% confidence interval [1.34; 1.88]). In Fig. 1b we add the LinkedIn connections to the advice networks and show that employees are linked to workers in other firms. Moreover, there are co-workers who are not linked in the advice network but are connected on LinkedIn.

To assess the spatial dimension of the links, we divide the connections collected from LinkedIn profiles to three geographic categories: local (Umeå), national (rest of Sweden), and global (outside Sweden). The geography of their global and national connections is displayed in Fig. 2a, b. As depicted in the figure, proximity clearly shapes the geography of the networks. The largest number of links, hardly surprisingly, is to 


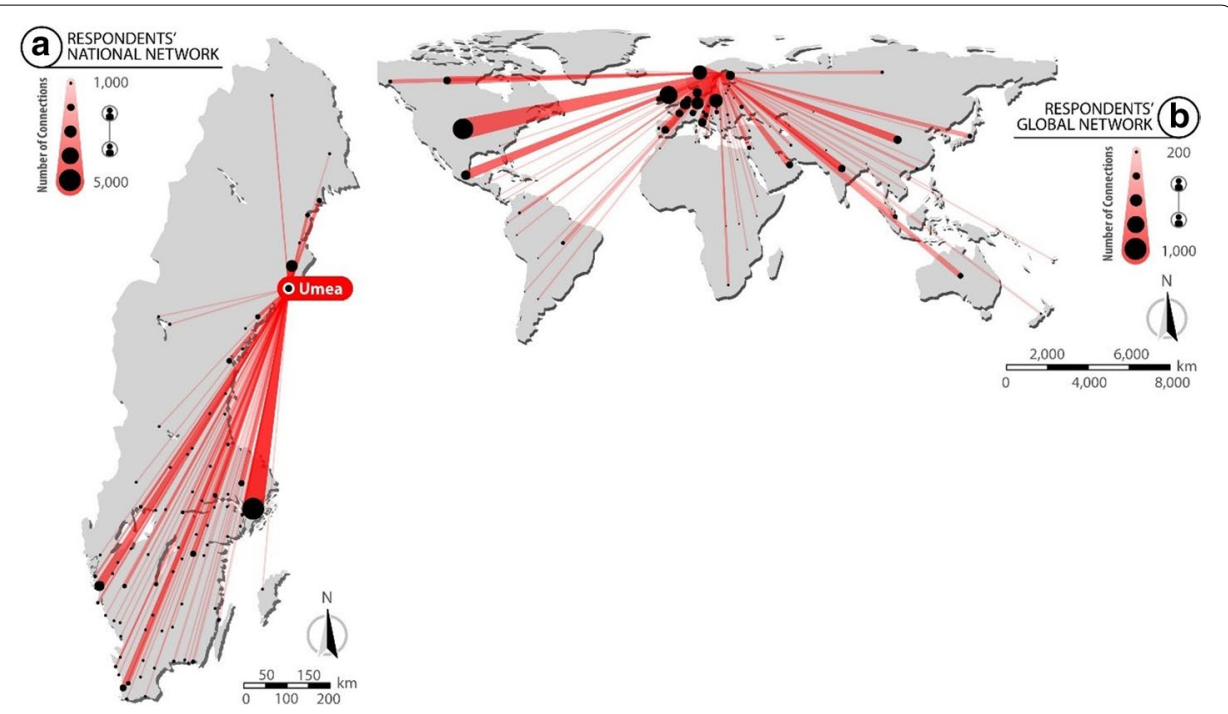

Fig. 2 Geography of respondents' national (a) and global (b) networks. Node size represents number of connections. Links tend to connect the region to major cities or countries, but geographic proximity also matters

Table 1 Summary statistics of respondents' skills and LinkedIn connections

\begin{tabular}{|c|c|c|c|c|c|c|}
\hline & Skills & & Linke & nnections & oondent & \\
\hline & Skills by respondent & $\begin{array}{l}\text { Frequency } \\
\text { of skills }\end{array}$ & Local & National & Global & Total \\
\hline Mean & 17.6 & 3.11 & 57.7 & 73.1 & 41.2 & 172.0 \\
\hline SD & 8.93 & 6.75 & 61.0 & 109.5 & 97.2 & 191.7 \\
\hline Min & 2 & 1 & 2 & 0 & 0 & 3 \\
\hline Max & 46 & 76 & 311 & 761 & 582 & 998 \\
\hline N & 150 & 847 & 125 & 125 & 125 & 125 \\
\hline
\end{tabular}

the capital city of Stockholm. Although the other two metropolitan regions (Gothenburg in the West and Malmö in the South) indeed both have a significant number of connections, the neighbouring city of Skellefteå in the North also stands out. Looking at the global (international) connections, although the single country with the most connections is the US, nearby European countries (UK, Norway, Poland) dominate.

Based on the respondents' LinkedIn profiles, it is then possible to collect data on their skills. We observe 2639 skill listings from 150 respondents, leading to 847 different skills being represented in the dataset. This means that one person has an average of 17.6 skills, with a minimum of two and a maximum of 46 skills for one person. The most popular skill is possessed by 76 respondents; however, an average skill is only possessed by 3.11 respondents (Table 1 ).

We have information on the location of LinkedIn connections for 125 respondents. On average, they have 57.7 local, 73.1 Swedish non-local, and 41.2 foreign contacts. Considering all the LinkedIn connections, the respondents have 172 connections on average (Table 1). 
The workers' skills are analysed using two types of measures. First, we define the similarity of skills between workers using the Jaccard measure (the number of common skills between two workers divided by the total number of skills they have together):

$$
J_{p q}=\frac{\left|S_{p} \cap S_{q}\right|}{\left|S_{p} \cup S_{q}\right|}
$$

where $J_{p q}$ is the similarity measure between individuals $p$ and $q$, and $S_{p}$ and $S_{q}$ are their skill sets, respectively.

Second, we assess how related their non-similar skills are, using a co-occurrence-based approach. In this technique, we define two skills as related if they often occur together in individuals' skill profiles. This is quantified based on the ratio of how often they occur together in the profiles compared to what we expect by random chance, applying the measurement by Teece et al. (1994) that was originally developed for product portfolios within firms:

$$
t_{i j}=\frac{C_{i j}-\mu_{i j}}{\sigma_{i j}},
$$

where $t_{i j}$ is the relatedness measure, $C_{i j}$ is the observed number co-occurrences of the skills, $\mu_{i j}$ is the expected value of co-occurrence in a random distribution of the skills, and $\sigma_{i j}$ is its standard deviation assuming binomial distribution. The formula of expected co-occurrence is $\mu_{i j}=\frac{n_{i} n_{j}}{K}$ and of standard deviation is $\sigma_{i j}^{2}=\mu_{i j} \frac{1-n_{i}}{K} \frac{K}{K-1}$, where $K$ is the number persons and $n$ is the observed frequency of the skill.

Figure 3 represents the relatedness landscape of the skills using the definition in Eq. 2. Similar skills cluster together, which we build upon when grouping and labelling these groups by characteristic features of included skills. Interestingly, management-related skills (e.g. Public Relations and Decision Making) are not related to engineering (e.g. System Design, Database, Engineering) or analytical skills (e.g. Visuals, Analysis and Modelling), but more to Finance and Sales. Strongly related skill groups are, for example, Finance and Sales, Artificial Intelligence (AI), and Investments and Business Intelligence. Audio in itself is a rather distinct group of skills that is not very connected to other ICT skills, while Knowledge Management has a transcending character.

Having defined the relatedness of the skills, we measure the degree of skill relatedness $R_{p q}$ between every pair of individuals $p$ and $q$ by taking the average relatedness for each combination of person-skills:

$$
R_{p q}=\sum_{i \in S_{p}} \sum_{j \in S_{q}, i \neq j} \frac{t_{i j}}{\left|S_{p}\right|\left|S_{q}\right|-2\left|S_{p} \cap S_{q}\right|},
$$

where $S_{p}$ and $S_{q}$ are the skill sets of $p$ and $q$.

When measuring skill similarity and relatedness of skills from LinkedIn data, we must be aware that skill sets displayed on LinkedIn can be endogenously correlated with LinkedIn networks. Users can add their own skills on the platform, but skills can also be added via "endorsement". In this case, the platform asks one's connections to endorse the individual with a set of suggested skills; while the exact algorithm of this recommendation system is not publicly available, it might influence the tie creation. 


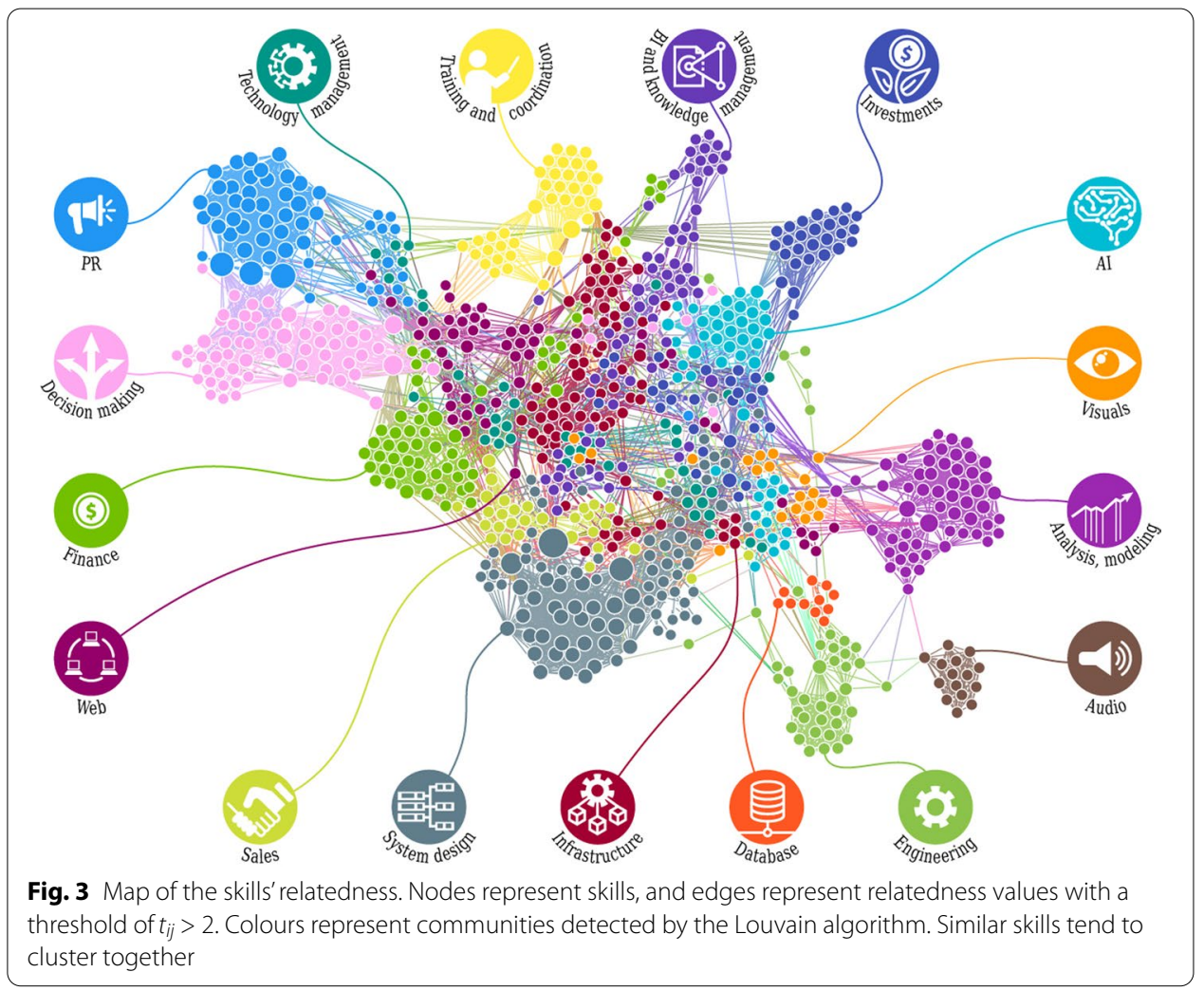

\section{Results}

\section{Skill relatedness and co-worker networks}

Figure 4 contains distributions of average relatedness (Fig. 4a, b) and similarity (Fig. 4c, d) of individuals with colleagues in the firm and with colleagues who are connected. Figure 4a illustrates that the average relatedness between co-workers in the same firm is higher than between random persons in the sample who are not coworkers. Further, we find that the relatedness of skills between those who are connected on LinkedIn does not differ from the relatedness of skills between co-workers. Zooming into relations within firms in Fig. 4b, we find that individual workers who are connected in the advice network are more skill-related on average than those who are not connected in the advice network. We can observe similar patterns regarding skill similarity. Co-workers within firms tend to have more similar skills than nonconnected workers in different firms (Fig. 4c). Hence, while there is a high degree of similarity and relatedness of skills between co-workers, which is expected given the formation of creative and more productive teams (Becker and Murphy 1992; Brennecke and Rank 2017; Neffke 2019), this is also the case concerning social connections reported on LinkedIn. Furthermore, employees tend to ask for advice from co-workers who have skills more similar to their own (Fig. 4d). In other words, workers are more likely to be connected to persons with related skills than to any random person, not only within the workplace but also to other firms and regions.

To analyse the statistical significance of these results, one has to consider that advice-seeking behaviour as well as skills may be correlated with individual attributes. 

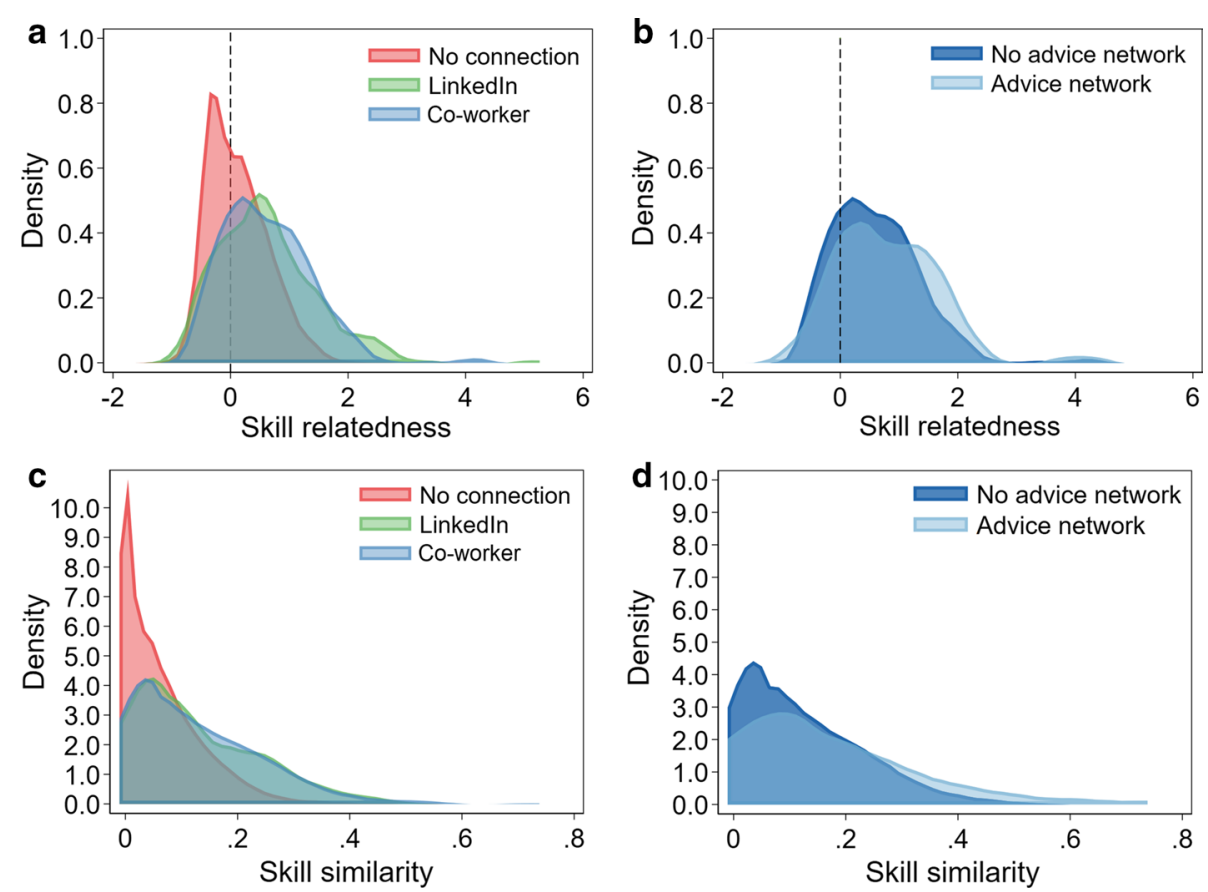

Fig. 4 Average relatedness $(\mathbf{a}, \mathbf{b})$ and similarity $(\mathbf{c}, \mathbf{d})$ of skills between pairs of respondents. $\mathbf{a}, \mathbf{c}$ Comparison of Linkedln connections (green)|Co-workers in firms (blue)|None (red). b, d Co-workers in the firms connected in advice network (light blue)|Not connected in advice network (dark blue). Indicates increased skill similarity and relatedness if employees work at the same firm or are connected on Linkedln, and especially if they ask each other for advice

Therefore, in our models we include work experience, type of job (junior professional, senior professional, or manager), sex, and firm size as control variables. Furthermore, similarity and relatedness are measured for each dyad, while we actually observe attributes on the individual level. In this case, standard errors tend to be underestimated in OLS specifications and significance levels are lower (Snijders and Bosker 2011). To obtain correct estimates, we use linear probability models with clustered standard errors. Indeed, if estimating OLS models without clustered standard errors we obtained similar results but also slightly more significant estimates. Our data structure is a specific case in which observations are classified by intersections of overlapping groups, as a dyad is in the intersection of two individuals. We therefore cluster standard errors according to this cross-classified structure. Accordingly, we estimate the following equation:

$$
L_{p q}=\alpha+\beta_{1} R_{p q}+\beta_{2} J_{p q}+\gamma \text { Controls }_{p}+\xi_{p}+\xi_{q}+\varepsilon_{p q},
$$

where $L_{p q}=1$ if person $p$ asks advice from person $q$ and 0 otherwise, while $\xi$ and $\varepsilon$ are the error terms on the individual and dyad levels, respectively. Note that even in these models we model dyads, but do not control for structural effects within the information networks (transitivity, reciprocity), which may bias our estimates upwards (Wimmer and Lewis 2010).

Table 2 reports the estimates for the network of asking for advice in professional matters within the firm. Having more related skills (Column A) or more similar skills 
Table 2 The relationship between skill relatedness and skill similarity and links in the advice-seeking networks

\begin{tabular}{|c|c|c|c|}
\hline \multirow[t]{2}{*}{ Dependent variable } & \multicolumn{3}{|c|}{ Link in advice network } \\
\hline & (A) & (B) & (C) \\
\hline \multicolumn{4}{|l|}{ Independent variables } \\
\hline \multirow[t]{2}{*}{ Skill relatedness } & $0.0321^{* *}$ & & -0.0213 \\
\hline & $(0.0134)$ & & $(0.0202)$ \\
\hline \multirow[t]{2}{*}{ Skill similarity } & & $0.400^{* * *}$ & $0.517^{* * *}$ \\
\hline & & $(0.0970)$ & $(0.147)$ \\
\hline \multirow[t]{2}{*}{ Constant } & 0.0803 & 0.0742 & 0.0809 \\
\hline & $(0.0658)$ & $(0.0656)$ & $(0.0660)$ \\
\hline Controls $^{\mathrm{a}}$ & Yes & Yes & Yes \\
\hline \multicolumn{4}{|l|}{ Random effects } \\
\hline \multirow{2}{*}{ Individual (1) } & $0.0163^{* * *}$ & $0.0168 * * *$ & $0.0170^{* * *}$ \\
\hline & $(0.00376)$ & $(0.00384)$ & $(0.00388)$ \\
\hline \multirow[t]{2}{*}{ Individual (2) } & $0.00426^{*}$ & $0.00372^{*}$ & $0.00361^{*}$ \\
\hline & $(0.00228)$ & $(0.00220)$ & $(0.00218)$ \\
\hline \multirow[t]{2}{*}{ Dyad } & $0.0746^{* * *}$ & $0.0738^{* * *}$ & $0.0737^{* * *}$ \\
\hline & $(0.00410)$ & $(0.00405)$ & $(0.00405)$ \\
\hline Observations (dyads) & 910 & 910 & 910 \\
\hline
\end{tabular}

Coefficients (standard errors in parentheses) of linear probability models with clustered standard errors

a Controls: work experience (years), type of job (junior professional, senior professional or manager), gender, and firm size

${ }^{* * *} p \leq 0.01 ;{ }^{* *} p \leq 0.05 ;{ }^{*} p \leq 0.1$

(Column B) is associated with being connected in the advice network. In this sense, the answer to our first research question is that skill similarity and advice relations are related, similarly to related skills and advice relations. However, once the share of the same skills is controlled for, the relatedness of the non-similar skills does not have additional impact on advice relations (Column $\mathrm{C}$ ). This may indicate that while concentrations of complementary skills in a firm allow for both specialization and (related) diversity that induce individual wage premiums as well as firm performance (Boschma et al. 2009; Neffke 2019), the more qualitative content of co-worker interactions tends to be between employees with similar skills. Hence, on the scale of the firm, complementary skills induce spillovers although the more direct information flows are between similar agents. Based on a cross-sectional sample we cannot identify causality that similar skills imply network connections. An opposite direction of relations may also be present that by asking advice from colleagues, people get proficiency in their skills; and even with the controls we have, there may be unobserved factors influencing both skills and advice-seeking relations. The significant random effects on the individual (1) and individual (2) levels indicate that dyadic variance is clustered by the individuals, which justifies the choice of our modelling approach.

\section{Skill relatedness and the geography of co-worker ties}

The degree of skill similarity and relatedness varies depending on where these connections are located. Considering the geography of networks, on the one hand, a higher share of local contacts is associated with a higher relatedness of skills to other respondents in our sample $(\mathrm{r}=0.16, p<0.001)$, and a higher skill similarity $(\mathrm{r}=0.19)$. 

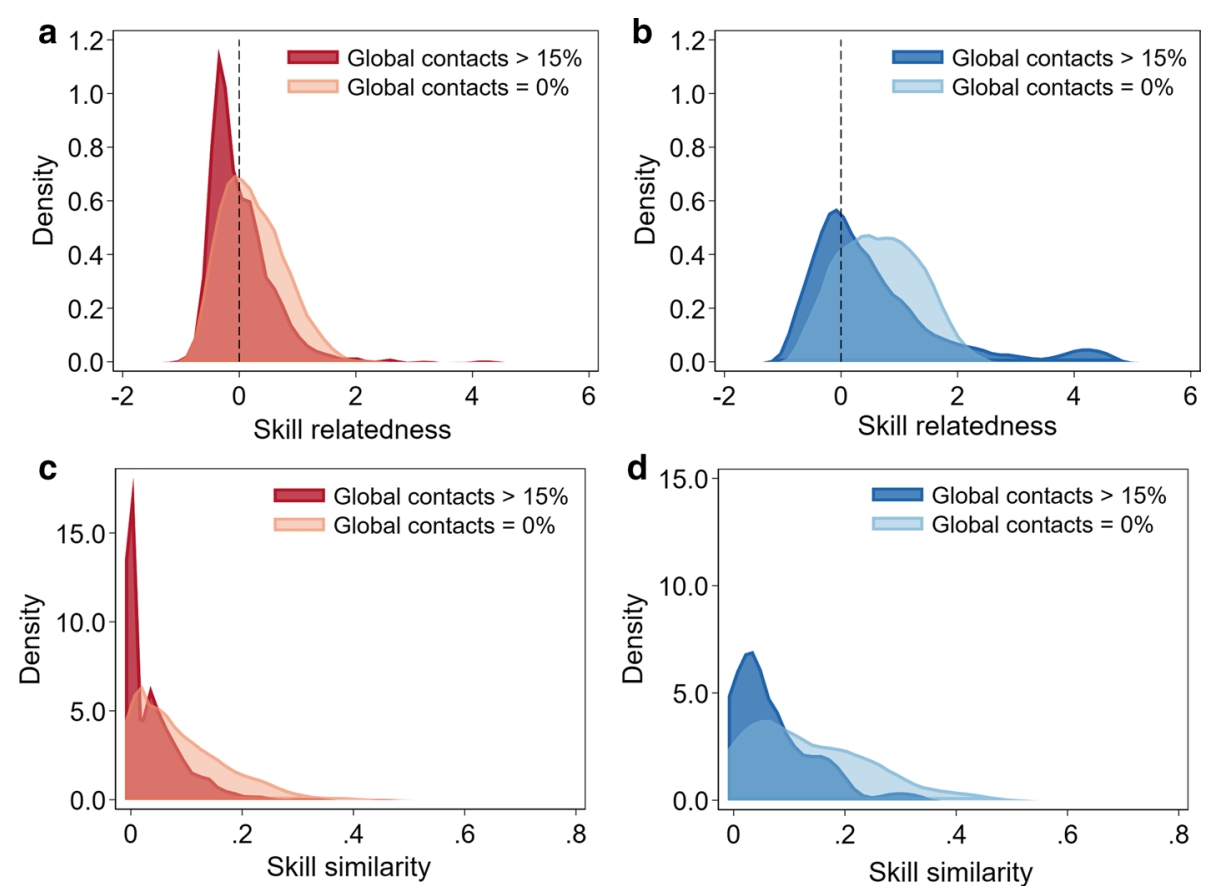

Fig. 5 Average relatedness $(\mathbf{a}, \mathbf{b})$ and similarity $(\mathbf{c}, \mathbf{d})$ of skills of persons with low/high share of global contacts. a, c All respondents; $\mathbf{b}, \mathbf{d}$ co-workers within firms. Suggests decreased skill relatedness and similarity of workers with more global contacts

On the other hand, the share of global contacts correlates negatively with relatedness of skills to other people $(\mathrm{r}=-0.14)$, as well as with skill similarity to other people $(\mathrm{r}=-0.16)$. Similar results can be found within firms for skill similarity: The skills of those who have more global contacts tend to be less similar to the skills of their present co-workers, while the skills of those with more local contacts tend to be more similar. Consequently, not only are global contacts more likely to introduce additional skill variety in itself; the persons who have these contacts are also less similar to their co-workers and hence act as a bridge between localized knowledge and more global knowledge. This trade-off is discussed in the conceptual cluster literature (cf. Bathelt et al. 2004), but to our knowledge has never been systematically empirically shown for a detailed regional cluster (Bathelt and Turi 2011). Figure 5 illustrates these findings regarding relatedness and similarity of skills of all respondents (Fig. 5a, c) and co-workers (Fig. 5b, d). Here we distinguish between two categories of workers: few global contacts $(0 \%$, representing the lowest quartile) versus many global contacts ( $>15 \%$, the highest quartile).

To test the statistical significance of the findings reported in Fig. 5, we estimate two additional regressions:

$$
\begin{aligned}
& R_{p q}=\alpha+\beta_{1} L O C_{p}+\beta_{2} \text { GLOB }_{p}+\beta_{3} N_{p}+\gamma \text { Controls }_{p}+\xi_{p}+\xi_{q}+\varepsilon_{p q} \\
& J_{p q}=\alpha+\beta_{1} L O C_{p}+\beta_{2} \text { GLOB }_{p}+\beta_{3} N_{p}+\gamma \text { Controls }_{p}+\xi_{p}+\xi_{q}+\varepsilon_{p q} .
\end{aligned}
$$


In both equations, $L O C$ denotes the share of local contacts within the person's LinkedIn connections, and GLOB represents the share of contacts outside Sweden. $N$ represents the size of the individual's network on LinkedIn, and Controls include sex, work experience, job type, and firm size.

We estimate both regressions on two samples. First, we consider all potential pairs of our respondents. The results obtained from these models are reported in Table 3, Panel A. Second, we restrict the sample to those dyads in which both persons work at the same firm (Table 3, Panel B).

The estimates suggest that a higher share of local contacts is associated with higher skill similarity and skill relatedness to co-workers as well as to other ICT workers in the region. Once the share of local contacts is considered, having a higher share of global contacts (instead of national ones) is only significant in the model on skill relatedness of all workers without individual- and firm-level control variables (Table 3, Panel A, Column 1). Nevertheless, the models are conclusive regarding our second research question, suggesting that globally embedded professionals' skills are less similar and less related compared to the skills of those who are locally embedded. The fact that the parameter of global contacts is not significant in Column 2 indicates the presence of selection effects as certain positions tend to be more globally oriented ${ }^{2}$. For example, having a high share of global connections is positively correlated with holding a managerial position. This confirms previous findings suggesting that certain hiring practices, especially involving more global-oriented employees, allow firms to tap into global sources of knowledge and thereby reduce the risk of cognitive inertia (Hassink 2010).

In fact, as indicated above, if at all impactful, a high share of global contacts implies a greater diversity of skills. Having many connections, disregarding the type of skills involved, is also associated with lower skill similarity and skill relatedness to other workers in the region. In all, this suggests two dimensions of local knowledge formation. First, workers in a local industry with a relatively high local network density tend to have a distinct set of skills and competences. Secondly, a large network, consisting of high shares of non-local links, is more likely to bring new types of skills to the region. Hence, regional clusters (in this case ICT) develop distinct local capabilities that might be different from similar activities in other regions. In the conceptual literature, this is usually referred to as untraded interdependencies that facilitate localized learning (Storper 1997; Malmberg and Maskell 2002). To avoid inertia and potential lock-in effects (Grabher 1993), it is therefore essential to also have global gatekeepers who can act as knowledge pipelines (Bathelt et al. 2004) as well as being able to recruit more global-oriented employees (Hassink 2010).

These findings correspond to our expectations, and verify that workers' local social connections are strongly related to the skill set accumulated within the firm or the region. On the contrary, those workers who have established global connections in the past tend to deviate the most from the local skill set. Taken together, considering the results presented in Figs. 4 and 5 as well as Table 2, distant connections are important sources for accessing new skills in closely related local co-worker networks. Hence, as

${ }^{2}$ In addition, N. of observations is somewhat lower in the equations with controls, due to missing values in the survey for control variables. 
Table 3 The relationship between geography of networks and skill relatedness and skill similarity

\begin{tabular}{|c|c|c|c|c|}
\hline \multirow{2}{*}{$\begin{array}{l}\text { Panel A } \\
\text { Dependent variable }\end{array}$} & \multicolumn{4}{|l|}{ All workers } \\
\hline & \multicolumn{2}{|c|}{ Skill relatedness } & \multicolumn{2}{|c|}{ Skill similarity } \\
\hline \multicolumn{5}{|l|}{ Independent variables } \\
\hline \multirow[t]{2}{*}{ Share of contacts global ${ }^{\mathrm{a}}$} & $-0.188^{*}$ & -0.114 & -0.0255 & 0.293 \\
\hline & $(0.102)$ & $(0.103)$ & $(0.0195)$ & $(0.362)$ \\
\hline \multirow[t]{2}{*}{ Share of contacts local ${ }^{\mathrm{a}}$} & $0.209^{* *}$ & $0.173^{*}$ & $0.0371^{*}$ & $0.517^{*}$ \\
\hline & $(0.104)$ & $(0.0964)$ & $(0.0198)$ & $(0.308)$ \\
\hline \multirow[t]{2}{*}{$N$ of connections ${ }^{b}$} & $-0.283^{* * *}$ & $-0.0296^{* * *}$ & $-0.0056^{* * *}$ & -0.0056 \\
\hline & $(0.0097)$ & $(0.0097)$ & $(0.0019)$ & $(0.0345)$ \\
\hline \multirow[t]{2}{*}{ Constant } & $0.147^{* *}$ & 0.00564 & $0.0665^{* * *}$ & 0.418 \\
\hline & $(0.0646)$ & $(0.0838)$ & $(0.0121)$ & $(0.266)$ \\
\hline Controls & No & Yes & No & Yes \\
\hline \multicolumn{5}{|l|}{ Random effects } \\
\hline \multirow[t]{2}{*}{ Individual (1) } & $0.000996^{* * *}$ & $0.0177^{* * *}$ & $0.0246^{* * *}$ & 0.0337 \\
\hline & $(0.000162)$ & $(0.00361)$ & $(0.00443)$ & $(0.0346)$ \\
\hline \multirow[t]{2}{*}{ Individual (2) } & $0.00164^{* * *}$ & $0.0642^{* * *}$ & $0.0516^{* * *}$ & $0.0845^{* *}$ \\
\hline & $(0.000204)$ & $(0.00862)$ & $(0.00687)$ & $(0.0403)$ \\
\hline \multirow[t]{2}{*}{ Dyad } & $0.00321 * * *$ & $0.237^{* * *}$ & $0.233^{* * *}$ & $0.466^{* * *}$ \\
\hline & $(5.74 \mathrm{e}-05)$ & $(0.00454)$ & $(0.00415)$ & $(0.0473)$ \\
\hline Observations (dyads) & 6,493 & 5,663 & 6,493 & 5,663 \\
\hline Panel B & \multicolumn{4}{|l|}{ Co-workers } \\
\hline Dependent variable & \multicolumn{2}{|c|}{ Skill relatedness } & \multicolumn{2}{|c|}{ Skill similarity } \\
\hline \multicolumn{5}{|l|}{ Independent variables } \\
\hline \multirow[t]{2}{*}{ Share of contacts global ${ }^{\mathrm{a}}$} & 0.338 & -0.114 & -0.0135 & 0.293 \\
\hline & $(0.389)$ & $(0.103)$ & $(0.0684)$ & $(0.362)$ \\
\hline \multirow[t]{2}{*}{ Share of contacts local ${ }^{a}$} & $0.649^{*}$ & $0.173^{*}$ & 0.0993 & $0.517^{*}$ \\
\hline & $(0.350)$ & $(0.0964)$ & $(0.0647)$ & $(0.308)$ \\
\hline \multirow[t]{2}{*}{$N$ of connections ${ }^{b}$} & 0.0257 & $-0.0296^{* * *}$ & -0.0058 & -0.0056 \\
\hline & $(0.0373)$ & $(0.0097)$ & $(0.0064)$ & $(0.0345)$ \\
\hline \multirow[t]{2}{*}{ Constant } & 0.236 & 0.00564 & $0.0930^{* *}$ & 0.418 \\
\hline & $(0.210)$ & $(0.0838)$ & $(0.0384)$ & $(0.266)$ \\
\hline Controls ${ }^{c}$ & No & Yes & No & Yes \\
\hline \multicolumn{5}{|l|}{ Random effects } \\
\hline \multirow[t]{2}{*}{ Individual (1) } & $0.0907^{* *}$ & $0.0177^{* * *}$ & $0.00548^{* * *}$ & 0.0337 \\
\hline & $(0.0444)$ & $(0.00361)$ & $(0.00145)$ & $(0.0346)$ \\
\hline \multirow[t]{2}{*}{ Individual (2) } & $0.0716^{* *}$ & $0.0642^{* * *}$ & $0.00199 * * *$ & $0.0845^{* *}$ \\
\hline & $(0.0353)$ & $(0.00862)$ & $(0.000718)$ & $(0.0403)$ \\
\hline \multirow[t]{2}{*}{ Dyad } & $0.464^{* * *}$ & $0.237^{* * *}$ & $0.00618^{* * *}$ & $0.466^{* * *}$ \\
\hline & $(0.0458)$ & $(0.00454)$ & $(0.000640)$ & $(0.0473)$ \\
\hline Observations (dyads) & 6493 & 5663 & 310 & 303 \\
\hline
\end{tabular}

Coefficients (standard errors in parentheses) of linear probability models with clustered standard errors

${ }^{* * *} p \leq 0.01 ;{ }^{* *} p \leq 0.05,{ }^{*} p \leq 0.1$

${ }^{a}$ Reference: national contacts

b Scale of $\mathrm{N}$. of connections is 100 links

c Controls: work experience (years), type of job (junior professional, senior professional, or manager), sex and firm size 


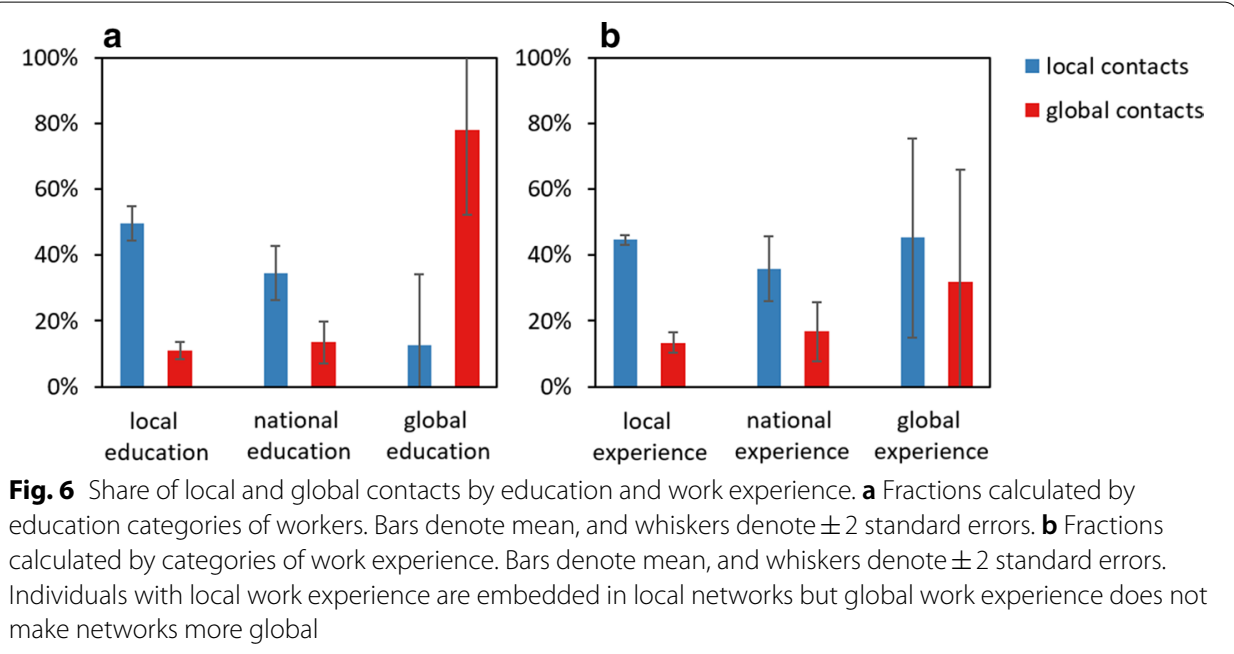

proposed in previous studies, a mix of local buzz and extra-local linkages is crucial for continuous renewal and competitiveness (Bathelt et al. 2004; Bathelt and Turi 2011).

\section{Extension: the role of education and work experience in creating local and global connections}

Professional contacts are not exogenously given to workers; rather, they evolve during their education and work histories (Dahl and Pedersen 2004; Snijders et al. 2013). Therefore, it is worth extending our analysis by examining how the location of workers' education and their work experience shape the geography of networks and the degree of skill similarity and relatedness.

We divided employees' education and work experience into three categories: local, national, and global, akin to the categorization of LinkedIn connections in Tables 1 and 3. This assignment is based on the minimum distance rule, meaning that in cases in which the employee had both local and global education or work experience previously in their career, their education or work experience is defined as local.

In Fig. 6, we illustrate the strong correlation of the geography of network contacts with the geographical category of education (a) and its much weaker correlation with work experience (b). The more global (local) the education is, the more likely it is to have more global (local) connections. Work experience, however, has a smaller effect on the degree of local contacts, although global contacts are naturally slightly more common among workers with experience of working abroad.

Again, by means linear probability models with clustered standard errors, we assess whether the geography of education and work experience is not only related to the fraction of local vs. global contacts but also to the degree of skill similarity and relatedness. Our findings suggest that having a foreign education is associated with decreased skill similarity, compared to having a national education. However, there is no significant difference in the skill similarity and skill relatedness between different universities in Sweden. Compared to those educated abroad, workers educated in Sweden tend to have a higher degree of skill relatedness to other workers (Table 4, Column 1). However, while we find no significant associations between having foreign work experience and skill 
Table 4 The impact of education and work experience on skill relatedness and skill similarity

\begin{tabular}{|c|c|c|}
\hline Dependent variable & Skill relatedness & Skill similarity \\
\hline \multicolumn{3}{|l|}{ Work experience ${ }^{\mathrm{a}}$} \\
\hline \multirow[t]{2}{*}{ Local } & $0.0868^{* *}$ & 0.00995 \\
\hline & $(0.0419)$ & $(0.00880)$ \\
\hline \multirow[t]{2}{*}{ Foreign } & 0.138 & 0.0113 \\
\hline & $(0.165)$ & $(0.0275)$ \\
\hline \multicolumn{3}{|l|}{ Education $^{a}$} \\
\hline \multirow[t]{2}{*}{ Local } & 0.0434 & 0.00608 \\
\hline & $(0.0377)$ & $(0.00790)$ \\
\hline \multirow[t]{2}{*}{ Foreign } & $-0.296^{* * *}$ & $-0.0438^{*}$ \\
\hline & $(0.113)$ & $(0.0232)$ \\
\hline \multirow[t]{2}{*}{$N$ of connections ${ }^{b}$} & $-0.0454^{* * *}$ & $-0.0076^{* * *}$ \\
\hline & $(0.0090)$ & $(0.0019)$ \\
\hline \multirow[t]{2}{*}{ Constant } & -0.0234 & 0.0223 \\
\hline & $(0.0847)$ & $(0.0172)$ \\
\hline Controls ${ }^{c}$ & Yes & Yes \\
\hline \multicolumn{3}{|l|}{ Random effects } \\
\hline \multirow[t]{2}{*}{ Individual (1) } & $0.0150^{* * *}$ & $0.000779^{* * *}$ \\
\hline & $(0.00342)$ & $(0.000150)$ \\
\hline \multirow[t]{2}{*}{ Individual (2) } & $0.0768^{* * *}$ & $0.00204^{* * *}$ \\
\hline & $(0.0102)$ & $(0.000260)$ \\
\hline \multirow[t]{2}{*}{ Dyad } & $0.215^{* * *}$ & $0.00327^{* * *}$ \\
\hline & $(0.00454)$ & $(6.90 e-05)$ \\
\hline Observations (dyads) & 4694 & 4694 \\
\hline
\end{tabular}

Coefficients (standard errors in parentheses) of linear probability models with clustered standard errors

${ }^{* * *} p \leq 0.01 ;{ }^{* *} p \leq 0.05 ;{ }^{*} p \leq 0.1$

${ }^{a}$ Reference category: national

b Scale of $\mathrm{N}$. of connections is 100 links

c Controls: work experience (years), type of job (junior professional, senior professional, or manager), sex, and firm size

composition (Table 4, Column 2), having only local work experience increases the skill relatedness to other workers in the region.

Finding no effect of foreign work experience is not the result of controlling for having foreign education, as it is also insignificant when this control is omitted (not reported in table). It could rather be the result of the weak correlation between work histories and the geography of networks. We believe, however, that the reason behind this is technical: if respondents had not recently updated their LinkedIn profile, our measure for the geography of the networks is not valid. We see that workers with no Swedish work experience report an average of $40 \%$ local contacts, which might be explained by these workers not having updated their profiles after coming to Sweden. On the other hand, as a person's education experience usually does not change after they have entered the labour force, measuring education based on LinkedIn is less sensitive to the currency of the profiles. 


\section{Conclusions}

The primary aim of this paper was to open the "black box" on the relationship between firm-specific co-worker networks and external links across space, to assess whether the geography of ties condition the degree of skill similarity. Our question is motivated by recent contributions arguing that firms and regions alike need to diversify their knowledge base in order to stay competitive and avoid cognitive lock-in (Grabher 1993; Boschma 2005). Combining detailed survey data on the networks of 214 employees at 16 ICT firms in the city of Umeå, Sweden, with automated online collection of data on the professional networks of these individuals, we find that the geography of social connections indeed conditions the likelihood that firms (and hence regions) can access diverse knowledge.

Our findings suggest that there is a high relatedness of skills between co-workers, compared to any random employee in the regional ICT industry. This finding supports the notion that firms develop certain capabilities that distinguish them from other firms in the industry (e.g., Penrose 1959). It is also consistent with the literature on knowledge specialization (Becker and Murphy 1992; Kogut and Zander 1993) and the resource-based approach of organization (Madhok 2002). We do find here, however, that the prevalence of complementarities is not only contingent on present coworker networks but also characterizes professional networks via LinkedIn. Hence, workers are more likely to be connected to persons with related skills than any random person, not only within the workplace but also in other firms and regions. It is important to note that the observed correlation between the skills and being connected on LinkedIn might be positively biased by LinkedIn's own recommendation algorithm.

Moreover, the geography of these ties also determines the degree of having access to diverse knowledge. Workers with more local contacts tend to be more similar to their co-workers and also to have links to less diverse types of knowledge. This implies that recruiting key personnel with broader national and global connections can act as a bridge to the knowledge in those communities (cf. Bathelt et al. 2004; Hassink 2010). This spatial dimension is also partly related to the size of the network, as having more connections is associated with decreased skill similarity and skill relatedness to other workers in the region. This suggests that a large network, consisting of non-local links, is more likely to bring new skills to the region. For this global knowledge diversity to be absorbed and internalized in the local economy, a relatively coherent local knowledge base is required.

Finally, we show that the geographical location of education correlates with the geography of network contacts. We show that having a foreign education, compared to a local or national education, decreases skill similarity. Considering the relatedness of the non-similar skills, those of locally and nationally educated workers are the most similar to those of other workers in the region, while they are less related to those of workers with a foreign education. These findings thereby suggest that ICT-related educations in general are relatively similar across different national universities compared to foreign educations. In particular, this suggests a team-building mechanism based on "weak ties," whereby existing team members manage complementary teams with related skills by hiring local peers known to have similar educations but slightly different skill 
specializations. In other words, this points to the role of social networks in sustaining matching externalities in industry agglomerations (cf., Eriksson and Lengyel 2019).

In sum, this research makes two distinct contributions. Compared to previous research on advice networks that has identified the impact of formal positions and individual characteristics (e.g., Lazega and Van Duijn 1997; Agneessens and Wittek 2012), value similarity (Lazega et al. 2012), local or global identification (Lomi et al. 2014), and team membership (Brennecke and Rank 2016) in network formation, we have shown that advice networks are formed along the skills of individuals. We have thereby shown that, to develop mutual understanding and interactive learning, some similar or related skills are required between the two agents. Spatial proximity, as is often assumed in the literature (Storper and Venables 2004), is simply not enough. In this aspect, our conclusions are similar to Brennecke and Rank's (2017) analysis of collaborations of patenting inventors at a high-tech firm. Regarding the literature on knowledge flows in general, and labour mobility in particular, we have shown that the skill content of such links is conditioned by the geography of contacts: More globally connected workers are more likely to both have more diverse skills and are also connected to more diverse skills outside the firm, compared to less globally connected co-workers in the firm. However, this is greatly contingent on the type of job the worker has, as including such information largely absorbs the global "network effect". Therefore, the positive impact of skill similarity captured by education or industry experience in larger regions is not necessarily a function of a greater within-industry variety in larger regions (cf., Timmermans and Boschma 2014). Instead, our results suggest that local networks offer access to complementary related skills beyond what can be captured by educational codes (degrees), for example different skill specializations within degrees. Hence, university networks may ease the matching of related skills through weak ties by providing additional information on the specialization of peers.

Although we have explored interesting relationships between co-workers' skills and their networks, this study is not without its limitations, and many questions remain open for further research. For example, the body of data used in this study is relatively small and is confined to a specific geography and a specific industry. Using data on other ICT clusters could provide more robust estimates regarding what types of networks matter where, while including more diverse industries may reveal different trends. Furthermore, although we have controlled for firm size, our sample is relatively homogenous, containing only small and medium-sized companies, where male college-educated professionals dominate. Therefore, examining large MNEs or a study of another industry may uncover further, or different, mechanisms. As we have seen that some of these estimates are affected by the inclusion of individual attributes such as position in the firm and gender, further studies could delve more deeply into these differences to help explain differences in, for example, career progression and collaboration patterns among men and women. Further, we have shown that skills and networks are related, although our methodology cannot infer the direction of causality.

From the social network analysis perspective, it would be interesting to analyse how these two co-evolve over time, and how structural effects within networks, like transitivity, centrality or reciprocity contribute to this. Having access to longitudinal data could also allow for more robust estimates, controlling for both observed and unobserved 
individual attributes. In addition, from an organizational networks perspective, our findings may suggest that differences in the firms regarding the diversity or similarity of their workforce's skills imply different network structures, which support efficient cooperation. This could then be analysed in respect to wage formation and firm performance. For economic geography, our findings on the internal differences of skill composition within firms would suggest that greater consideration needs to be taken when analysing within- and between-regional knowledge and information networks. Regional aggregates may actually reveal only fragments of the potential trade-offs between local and non-local links.

\section{Acknowledgements}

The authors appreciate the comments received at the European Conference on Social Networks (Zürich, September 2019), the Sixth International Workshop on Industry Relatedness (Budapest, December 2019), and the Geography of Innovations Conference (Stavanger, January 2020).

\section{Authors' contributions}

LL was a major contributor to the statistical analyses and to writing the manuscript. GKC performed the data analysis, created visualizations, and contributed to writing the manuscript. AH implemented the survey and online social network data collections, and contributed to writing the manuscript. DT implemented the survey and online social network data collections. BL was a major contributor to writing the manuscript and creating visualizations. RE coordinated the survey data collection and the analysis, and was a major contributor to writing the manuscript. The design of the data collection was performed by all authors together. All authors read and approved the final manuscript.

\section{Funding}

This work was financed by the Swedish Research Council (grant number 2016-01803). Balázs Lengyel and László Lőrincz also acknowledge funding received from the Hungarian Scientific Research Fund (OTKA K-129207).

\section{Availability of data and materials}

The datasets generated and analysed during the current study are not publicly available, according to the consent given by the study respondents, but are available from the corresponding author on reasonable request.

Competing interests

The authors declare no conflicts of interest.

\section{Author details}

${ }^{1}$ Centre for Economic and Regional Studies, Institute of Economics, Budapest, Hungary. ${ }^{2}$ Laboratory for Networks, Technology and Innovation, Corvinus University of Budapest, Budapest, Hungary. ${ }^{3}$ Department of Geography, Umeå University, Umeå, Sweden. ${ }^{4}$ Institute for Analytical Sociology, Linköping University, Norrköping, Sweden. ${ }^{5}$ Department of Information Science, University of Zurich, Zurich, Switzerland. ${ }^{6}$ Agglomeration and Social Networks Lendület Research Group, Hungarian Academy of Sciences, Budapest, Hungary. ${ }^{7}$ Center for Regional Science, Umeå University, Umeå, Sweden.

Received: 29 February 2020 Accepted: 13 October 2020

Published online: 23 October 2020

\section{References}

Abdulkareem A, Frank MR, Sun L, AIShebli B, Hidalgo C, Rahwan I (2018) Unpacking the polarization of workplace skills. Sci Adv 4(7):eaao6030

Agneessens F, Wittek R (2012) Where do intra-organizational advice relations come from? The role of informal status and social capital in social exchange. Soc Netw 34(3):333-345

Aral S (2016) The future of weak ties. Am J Sociol 121:1931-1939

Aral S, Nicolaides C (2017) Exercise contagion in a global social network. Nat Commun 8(1):1-8

Arrow K (1962) Economic welfare and the allocation of resources for invention. In: Nelson RR (ed) The rate and direction of inventive activity: economic and social factors. Princeton University Press, Princeton, pp 609-626

Bailey M, Cao R, Kuchler T, Stroebel J, Wong A (2019) Social connectedness: measurement, determinants, and effects. J Econ Perspect 32(3):259-280

Bakshy E, Rosenn I, Marlow C, Adamic L (2012) The role of social networks in information diffusion. In: Proceedings of the 21st international conference on World Wide Web, pp 519-528

Balland PA, Belso-Martínez JA, Morrison A (2016) The dynamics of technical and business knowledge networks in industrial clusters: embeddedness, status, or proximity? Econ Geogr 92(1):35-60

Bathelt H, Turi P (2011) Local, global and virtual buzz: the importance of face-to-face contact in economic interaction and possibilities to go beyond. Geoforum 42(5):520-529

Bathelt H, Malmberg A, Maskell P (2004) Clusters and knowledge: local buzz, global pipelines and the process of knowledge creation. Prog Hum Geogr 28(1):31-56

Becker G, Murphy KM (1992) Human capital and specialization. Quart J Econ 107:1137-1160 
Borgatti SP, Mehra A, Brass DJ, Labianca G (2009) Network analysis in the social sciences. Science 323(5916):892-895 Boschma R (2005) Proximity and innovation: a critical assessment. Reg Stud 39(1):61-74

Boschma RA, Frenken K (2010) The spatial evolution of innovation networks: a proximity perspective. In: Boschma RA, Martin R (eds) The handbook of evolutionary economic geography. Edward Elgar, Cheltenham, pp 120-135

Boschma R, Eriksson R, Lindgren U (2009) How does labor mobility affect the performance of plants? The importance of relatedness and geographical proximity. J Econ Geogr 9(2):169-190

Brennecke J, Rank ON (2016) The interplay between formal project memberships and informal advice seeking in knowledge-intensive firms: a multilevel network approach. Soc Netw 44:307-318

Brennecke J, Rank ON (2017) The firm's knowledge network and the transfer of advice among corporate inventors-a multilevel network study. Res Policy 46(4):768-783

Breschi S, Lissoni F (2009) Mobility of skilled workers and co-invention networks: an anatomy of localized knowledge flows. J Econ Geogr 9(4):439-468

Csáfordi Z, Lőrincz L, Lengyel B, Kiss KM (2020) Productivity spillovers through labor flows: productivity gap, multinational experience and industry relatedness. J Technol Transf 45(1):86-121

Dahl MS, Pedersen CØ (2004) Knowledge flows through informal contacts in industrial clusters: myth or reality? Res Policy 33(10):1673-1686

De Lange D, Agneessens F, Waege H (2004) Asking social network questions: a quality assessment of different measures. Metodol Zv 1(2):351-378

Dibiaggio L, Nasiriyar M, Nesta L (2014) Substitutability and complementarity of technological knowledge and the inventive performance of semiconductor companies. Res Policy 43(9):1582-1593

Eagle N, Macy M, Claxton R (2012) Network diversity and economic development. Science 328(6104):267-270

Eriksson R, Lengyel B (2019) Co-worker networks and agglomeration externalities. Econ Geogr 95(1):65-89

Eriksson R, Lindgren U (2009) Localized mobility clusters: impacts of labour market externalities on firm performance. J Econ Geogr 9(1):33-53

Fernandez RM, Su C (2004) Space in the study of labor markets. Annu Rev Sociol 30:545-569

Fitjar RD, Rodríguez-Pose A (2011) When local interaction does not suffice: sources of firm innovation in urban Norway. Environ Plan A 43(6):1248-1267

Glückler J (2007) Economic geography and the evolution of networks. J Econ Geogr 7(5):619-634

Grabher G (1993) The weakness of strong ties—-the lock-in of regional development in the Ruhr area. In: Grabher G (ed) The embedded firm. Routledge, London, pp 255-277

Granovetter M (1973) The weakness of strong ties. Am J Sociol 78:1360-1380

Guimera R, Uzzi B, Spiro J, Amaral LAN (2005) Team assembly mechanisms determine collaboration network structure and team performance. Science 308(5722):697-702

Hassink R (2010) Regional resilience: a promising concept to explain differences in regional economic adaptability? Camb J Reg Econ Soc 3(1):45-58

Helbing D, Brockmann D, Chadefaux T et al (2015) Saving human lives: what complexity science and information systems can contribute. J Stat Phys 158(3):735-781

Juhász S, Lengyel B (2018) Creation and persistence of ties in cluster knowledge networks. J Econ Geogr 18(6):1203-1226

Kogut B, Zander U (1993) Knowledge of the firm and the evolutionary theory of the multinational corporation. J Int Bus Stud 24(4):625-645

Lazega E, Van Duijn M (1997) Position in formal structure, personal characteristics and choices of advisors in a law firm: a logistic regression model for dyadic network data. Soc Netw 19(4):375-397

Lazega E, Mounier L, Snijders T, Tubaro P (2012) Norms, status and the dynamics of advice networks: a case study. Soc Netw 34(3):323-332

Lazer D, Pentland A, Adamic L, Aral S, Barabasi AL, Brewer D, Christakis N (2009) Computational social science. Science 323(5915): $721-723$

Lengyel B, Eriksson RH (2017) Co-worker networks, labour mobility, and productivity growth in regions. J Econ Geogr 17(3):635-660

Lomi A, Lusher D, Pattison PE, Robins G (2014) The focused organization of advice relations: a study in boundary crossing. Organ Sci 25(2):438-457

Madhok A (2002) Reassessing the fundamentals and beyond: Ronald Coase, the transaction cost and resource-based theories of the firm and the institutional structure of production. Strateg Manag J 23(6):535-550

Malmberg A, Maskell P (2002) The elusive concept of localization economies: towards a knowledge-based theory of spatial clustering. Environ Plan A 34(3):429-449

Neffke F (2019) The value of complementary coworkers. Sci Adv 5(12):eaax3370. https://doi.org/10.1126/sciadv.aax3370

Neffke F, Henning M (2013) Skill relatedness and firm diversification. Strateg Manag J 34(3):297-316

Park J, Wood IB, Jing E, Nematzadeh A, Ghosh S, Conver MD, Ahn Y-Y (2019) Global labor flow network reveals the hierarchical organization and dynamics of geo-industrial clusters. Nat Commun 10:3449

Penrose E (1959) The theory of the growth of the firm. Wiley, New York

Singh J (2005) Collaborative networks as determinants of knowledge diffusion patterns. Manag Sci 51(5):756-770. https ://doi.org/10.1287/mnsc.1040.0349

Snijders TA, Bosker RJ (2011) Multilevel analysis: an introduction to basic and advanced multilevel modeling. Sage, Thousand Oaks

Snijders TA, Lomi A, Torló VJ (2013) A model for the multiplex dynamics of two-mode and one-mode networks, with an application to employment preference, friendship, and advice. Soc Netw 35(2):265-276

Storper M (1997) The regional world: territorial development in a global economy. Guilford press, New York

Storper M, Venables AJ (2004) Buzz: face-to-face contact and the urban economy. J Econ Geogr 4(4):351-370

Teece DJ, Rumelt R, Dosi G, Winter S (1994) Understanding corporate coherence: theory and evidence. J Econ Behav Organ 23(1):1-30

Ter Wal AL, Alexy O, Block J, Sandner PG (2016) The best of both worlds: the benefits of open-specialized and closeddiverse syndication networks for new ventures' success. Adm Sci Q 61(3):393-432 
Timmermans B, Boschma R (2014) The effect of intra-and inter-regional labour mobility on plant performance in Denmark: the significance of related labour inflows. J Econ Geogr 14(2):289-311

Tortoriello M, Krackhardt D (2010) Activating cross-boundary knowledge: the role of Simmelian ties in the generation of innovations. Acad Manag J 53(1):167-181. https://doi.org/10.5465/amj.2010.48037420

Tóth G, Lengyel B (2019) Inter-firm inventor mobility and the role of co-inventor networks in producing high-impact innovation. J Technol Transf. https://doi.org/10.1007/s10961-019-09758-5

Tzabbar D, Bruno C, Breschi S (2018) The effect of social and knowledge interdependencies on employee mobility and entrepreneurship. Acad Manag Proc 2018(1):10250

Ugander J, Backstrom L, Marlow C, Kleinberg J (2012) Structural diversity in social contagion. Proc Natl Acad Sci 109(16):5962-5966

Vedres B (2017) Forbidden triads and creative success in jazz: the Miles Davis factor. Appl Netw Sci 2(1):31

Wimmer A, Lewis K (2010) Beyond and below racial homophily: ERG models of a friendship network documented on Facebook. Am J Sociol 116(2):583-642

\section{Publisher's Note}

Springer Nature remains neutral with regard to jurisdictional claims in published maps and institutional affiliations.

\section{Submit your manuscript to a SpringerOpen ${ }^{\circ}$} journal and benefit from:

- Convenient online submission

- Rigorous peer review

- Open access: articles freely available online

- High visibility within the field

- Retaining the copyright to your article

Submit your next manuscript at $\boldsymbol{\Delta}$ springeropen.com 